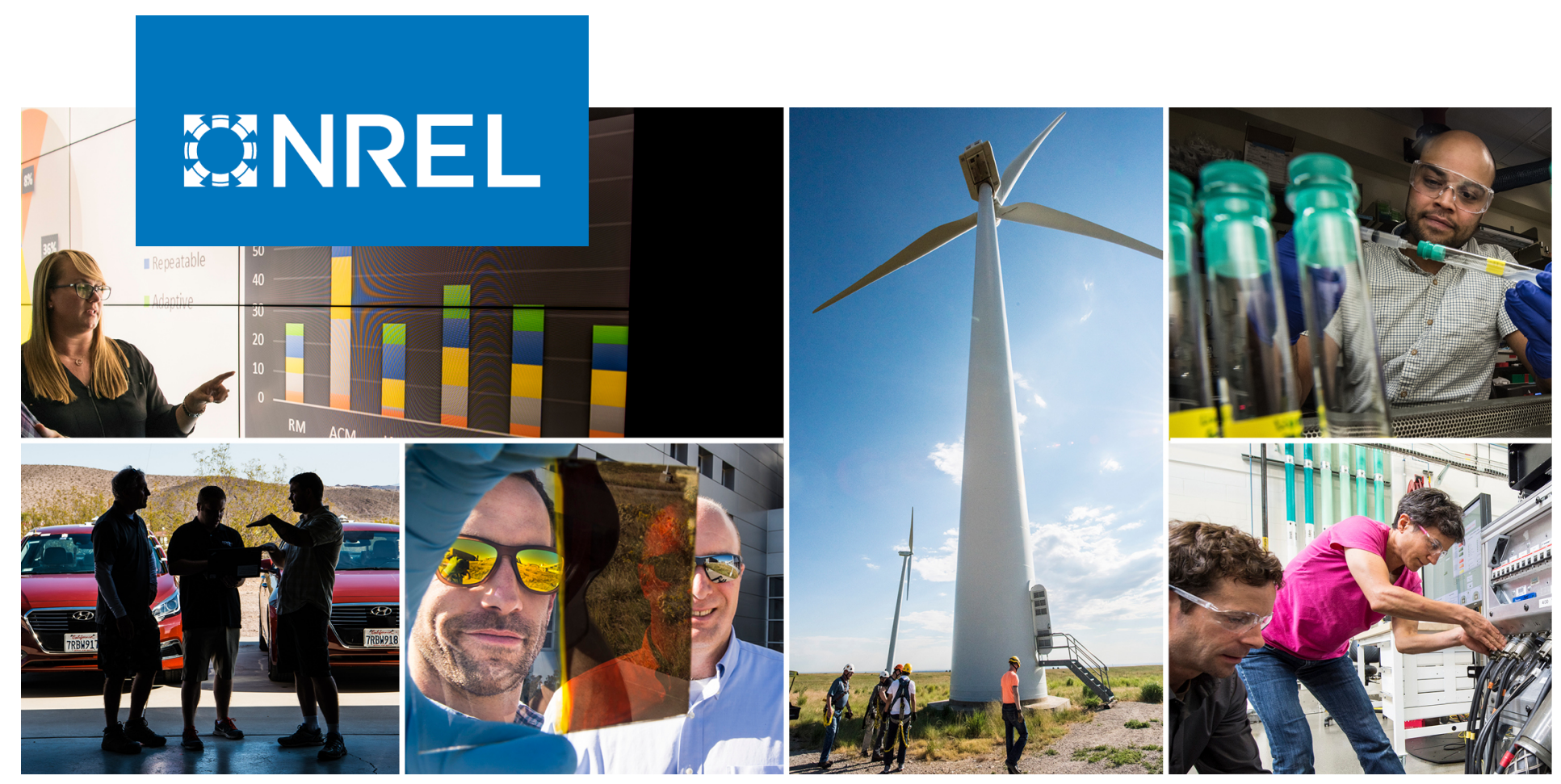

\title{
Development and Demonstration of a Class 6 Range-Extended Electric Vehicle for Commercial Pickup and Delivery Operation
}

\section{Preprint}

Matthew Jeffers ${ }^{1}$, Eric Miller ${ }^{1}$, Kenneth Kelly ${ }^{1}$, John Kresse ${ }^{2}, \mathrm{Ke} \mathrm{Li}^{2}$, Jesse Dalton ${ }^{2}$, Michael Kader ${ }^{3}$, and Cole Frazier ${ }^{3}$

1 National Renewable Energy Laboratory

2 Cummins Inc

3 Southwest Research Institute

Presented at the 2020 SAE International WCX Digital Summit June 16-18, 2020

NREL is a national laboratory of the U.S. Department of Energy

Office of Energy Efficiency \& Renewable Energy

Operated by the Alliance for Sustainable Energy, LLC

This report is available at no cost from the National Renewable Energy Laboratory (NREL) at www.nrel.gov/publications.
Conference Paper

NREL/CP-5400-78181

October 2020 


\section{GNREL}

Development and Demonstration of a Class 6 Range-Extended Electric Vehicle for Commercial Pickup and Delivery Operation

\section{Preprint}

Matthew Jeffers ${ }^{1}$, Eric Miller ${ }^{1}$, Kenneth Kelly ${ }^{1}$, John Kresse ${ }^{2}, \mathrm{Ke} \mathrm{Li}^{2}$, Jesse Dalton ${ }^{2}$, Michael Kader ${ }^{3}$, and Cole Frazier ${ }^{3}$

1 National Renewable Energy Laboratory

2 Cummins Inc

3 Southwest Research Institute

\section{Suggested Citation}

Jeffers, Matthew, Eric Miller, Kenneth Kelly, John Kresse, Ke Li, Jesse Dalton, Michael Kader, and Cole Frazier. 2020. Development and Demonstration of a Class 6 RangeExtended Electric Vehicle for Commercial Pickup and Delivery Operation: Preprint. Golden, CO: National Renewable Energy Laboratory. NREL/CP-5400-78181 https://www.nrel.gov/docs/fy210sti/78181.pdf.

NREL is a national laboratory of the U.S. Department of Energy Office of Energy Efficiency \& Renewable Energy Operated by the Alliance for Sustainable Energy, LLC

This report is available at no cost from the National Renewable Energy Laboratory (NREL) at www.nrel.gov/publications.

Contract No. DE-AC36-08GO28308
Conference Paper NREL/CP-5400-78181

October 2020

National Renewable Energy Laboratory 15013 Denver West Parkway Golden, CO 80401

303-275-3000 • www.nrel.gov 


\section{NOTICE}

This work was authored in part by the National Renewable Energy Laboratory, operated by Alliance for Sustainable Energy, LLC, for the U.S. Department of Energy (DOE) under Contract No. DE-AC36-08GO28308. Funding provided by the U.S. Department of Energy Office of Energy Efficiency and Renewable Energy Vehicle Technologies Office. The views expressed herein do not necessarily represent the views of the DOE or the U.S. Government. The U.S. Government retains and the publisher, by accepting the article for publication, acknowledges that the U.S. Government retains a nonexclusive, paid-up, irrevocable, worldwide license to publish or reproduce the published form of this work, or allow others to do so, for U.S. Government purposes.

This report is available at no cost from the National Renewable Energy Laboratory (NREL) at www.nrel.gov/publications.

U.S. Department of Energy (DOE) reports produced after 1991 and a growing number of pre-1991 documents are available free via www.OSTI.gov.

Cover Photos by Dennis Schroeder: (clockwise, left to right) NREL 51934, NREL 45897, NREL 42160, NREL 45891, NREL 48097, NREL 46526.

NREL prints on paper that contains recycled content. 


\section{Abstract}

Range-extended hybrids are an attractive option for medium- and heavy-duty commercial vehicle fleets because they offer the efficiency of an electrified powertrain with the driving range of a conventional diesel powertrain. The vehicle essentially operates as if it was purely electric for most trips, while ensuring that all commercial routes can be completed in any weather conditions or geographic terrain. Fuel use and point-source emissions can be significantly reduced, and in some cases eliminated, as many shorter routes can be fully electrified with this architecture.

Under a U.S. Department of Energy (DOE)-funded project for Medium- and Heavy-Duty Vehicle Powertrain Electrification, Cummins has developed a plug-in hybrid electric Class 6 truck with a range-extending engine designed for pickup and delivery application. The National Renewable Energy Laboratory (NREL) assisted by developing representative workday drive cycles for Class 6 operation and an adapted cycle to enable vehicle track testing. A novel, automated driving system was utilized by Southwest Research Institute (SwRI) to improve the repeatability of the track testing conducted to quantify vehicle energy consumption. Cummins used a drivetrain model to design the hybrid control system for increased fuel savings. The control system functionality and fuel savings objective of $50 \%$ or more were confirmed by track testing described in this paper.

\section{Introduction}

In 2016, Cummins received an award under a DOE competitive solicitation for Medium- and Heavy-Duty Vehicle Powertrain Electrification to develop and demonstrate a hybrid Class 6 pickup and delivery (P\&D) truck. The project team included PACCAR for vehicle integration support. Argonne National Laboratory and The Ohio State University assisted Cummins with vehicle simulation and hybrid controls development. Drive cycle development and analysis was provided by NREL. SwRI conducted the vehicle track testing for Cummins using an automated driving system.

The primary objective of the project was to electrify the vehicle powertrain and accessories to reduce fuel consumption by $50 \%$ or more while continuing to meet the requirements of existing trucks in the Class 6 P\&D market. This was accomplished with a plug-in hybrid electric vehicle architecture, which is capable of highly efficient all-electric driving and aggressive regenerative braking. A downsized diesel engine/generator was included as a range extender to recharge the battery or drive the vehicle as a conventional diesel when sufficient power is not available from the battery. A hybrid control strategy was developed to optimize the use of stored electrical energy based on the expected service requirements for each day.

This range-extending plug-in hybrid electric vehicle architecture with charge-depleting approach to maximize fuel savings through strategic use of all-electric driving is best evaluated on a daily basis. A representative duty cycle for testing must capture a full day of operation in both variability and duration. A comparison of average fuel efficiency for a typical 20- to 60-minute dynamometer drive cycle is not adequate to evaluate the performance of the vehicle energy management system designed to minimize total fuel use for the entire vehicle workday. For this reason, NREL previously developed representative drive cycles for Class 6 P\&D operation [1]. NREL investigated real-world driving data in the Fleet DNA database and performed a statistical analysis on the set of conventionally fueled Class 6-7 P\&D vehicles to identify the appropriate length and duration of the desired cycle [2]. The study found that $90 \%$ of recorded days had less than 80 vehicle miles traveled and $95 \%$ of days had less than 100 vehicle miles traveled. Thus, the primary target cycle was developed to represent an 80-mile workday, and a secondary cycle represented a 100-mile workday. The composite drive cycles were constructed from individual recorded trips using NREL's Drive-Cycle Rapid Investigation, Visualization, and Evaluation (DRIVE) tool [3]. These workday drive cycles were used by researchers at Cummins to guide system component sizing, optimize hybrid controls, simulate vehicle performance, and verify realized fuel savings for the hybrid truck.

\section{Approach}

\section{Hybrid Vehicle Development}

Upon developing the representative duty cycles for Class 6-7 P\&D applications, a component sizing study was conducted by Cummins using powertrain and complete vehicle models - specifically, models of transmission, final drive ratio, energy storage system, traction motor, and range-extending engine/generator were used for sizing simulations. The goal was to match performance metrics (maximum vehicle speed, acceleration, gradeability, etc.) of the range-extended electric vehicle (EV) to its conventional counterpart, while achieving fuel savings greater than $50 \%$.

Two MATLAB Simulink-based simulation models were developed for component sizing and validation: a conventional powertrain model and a range-extended EV powertrain model. The models are forward looking, which include vehicle dynamics, a driver model, diesel engine dynamics and fuel consumption map, electric machine dynamics and efficiency map, battery dynamics and an energy management system. A large design of experiments for various components and routes was carried out utilizing the two vehicle models. The transmission, final drive ratio, and traction motor were determined first based on a number of factors: performance metrics, weights, prices, and availability of the components. The performance metrics include matching the acceleration, startability, and gradeability of a conventional vehicle in the same class. The size of the battery was then determined based on the target fuel consumption reduction. The battery size was used as the energy requirement to the battery supplier and a prototype battery was built. Figure 1 shows the modeled fuel consumption reduction with the final battery on various real-world Class 6 vehicle drive cycles, and the range-extended EV was able to exceed the $50 \%$ target on more than $80 \%$ of the routes. 


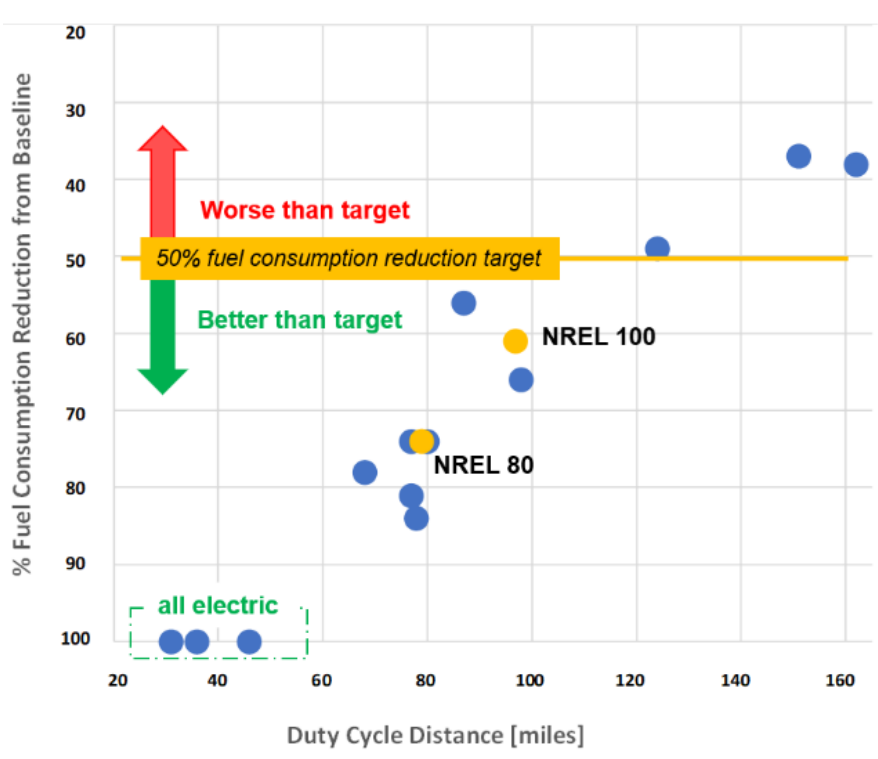

Figure 1 Fuel consumption reduction on various duty cycles with the chosen battery size

The final powertrain architecture is shown in Figure 2. A 175-kW permanent magnet motor and a four-speed automatic transmission with stop-start feature to eliminate idling fuel loss were chosen for the traction side of the powertrain. A $130-\mathrm{kW}$ generator mechanically coupled with a Cummins 4.5-L diesel engine to produce electric power routed directly to the traction motor or to charge the battery. The battery is comprised of nickel-manganese-cobalt (NMC) cells and has a total energy storage capacity of $122 \mathrm{kWh}$.

The powertrain was first assembled in a test cell and benchmarked against a conventional powertrain (a 6.7-L diesel engine and a six-speed automatic transmission). The test cell results were used for control development and calibration tuning. The powertrain was installed in the truck chassis thereafter. A schematic of the vehicle is shown in Figure 3. Besides the powertrain, an AC-DC onboard charger was installed to support SAE J1772 Level 2 charging. A DC-DC converter and electrified accessories were designed and integrated on the vehicle.

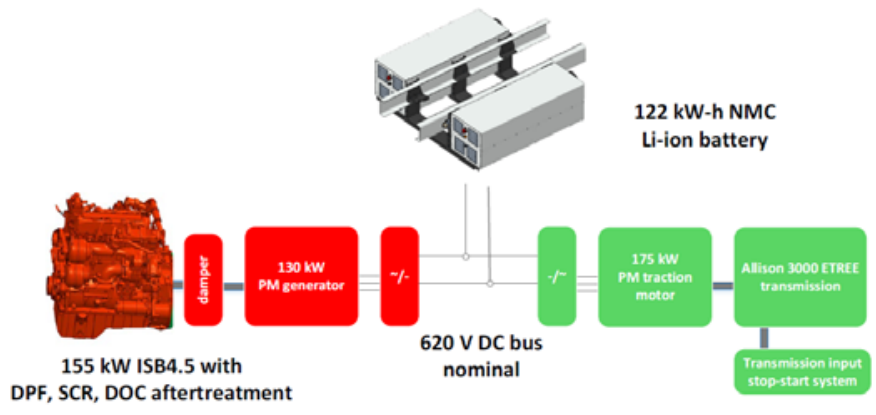

Figure 2 Schematic of Cummins range-extended EV powertrain architecture

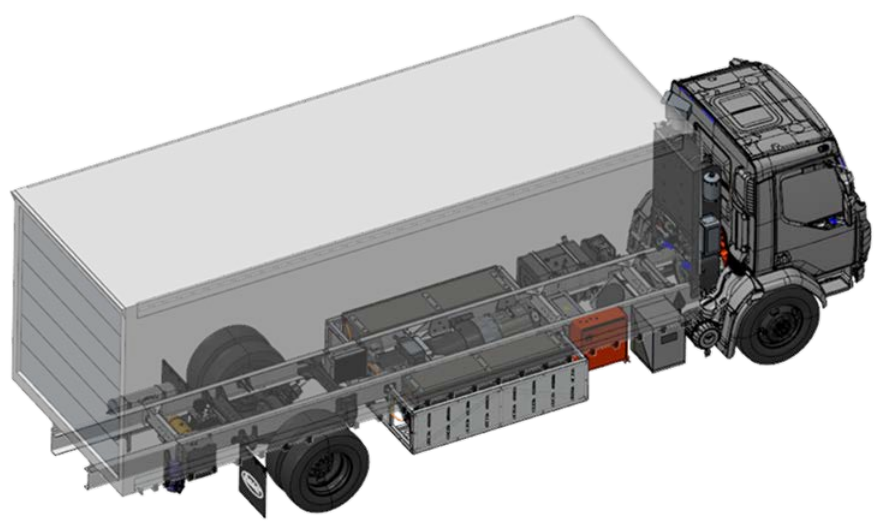

Figure 3 Range-extended electric vehicle design

A range-extended electric vehicle (REEV) is an attractive alternative to a purely battery-electric vehicle (BEV) for commercial fleets. It allows sufficient EV range to complete most missions without using the engine while offering flexibility and robustness to environmental conditions and unexpected deviations in duty cycle. Range-extending capabilities reduce risk to fleet operations. Specifically, if the vehicle was parked outdoors overnight in winter, the driver would need to wait for the battery to warm up before he/she can drive a BEV. However, for the REEV, the driver can start right away with the range extender providing power directly to the traction motor while the battery is warming up. Furthermore, for a BEV during a hot summer day when the battery has been exercised heavily and its temperature is reaching its derating limit, the traction power needs to be reduced/derated for the rest of the mission. However, for the REEV, the range extender can be turned on to take the majority of the load from the battery as well as provide traction power. Another scenario is the vehicle operating in a region where a charging station is not available, and the range extender can be used to charge the battery just as a stationary charger. If properly sized and designed, a REEV can achieve a payback period equivalent to that of a conventional vehicle. However, there are also a few challenges with the range extender operation.

One of the challenges is to fully utilize the grid energy to reduce fuel consumption. Due to the uncertainty of the routes, it's difficult to schedule the exact timing and power level of the range extender throughout the mission. Many of the existing strategies are so-called charge depleting and charge sustaining strategies, in which the vehicle will be in pure EV mode until the battery state of charge (SOC) drops to a minimum level, at which point the range extender will be turned on to maintain the minimum SOC level. The problem with this approach is that if the minimum SOC level is set too low, the vehicle will be derated if there is large energy demand ahead (long traffic jam, long hill, etc.). On the other hand, if the minimum SOC level is set too high, the grid energy is not fully utilized.

A novel control strategy was designed to reduce the chance of derated performance while optimally utilizing grid energy. Specifically, a Human-Machine-Interface (Figure 4) was programmed and installed in the cabin of the vehicle, on which the driver will enter the estimated travel distance for the day's mission. Upon receiving the trip information, the algorithm will decide a target SOC for the trip. The result is a "blended" SOC tracking trajectory (Figure 5), which allows pure EV modes for initial portions of the mission, and schedules the range extender power automatically throughout the rest of the mission to track the SOC target. The strategy ensures the full utilization of the grid energy and eliminates the need for derated operation. 


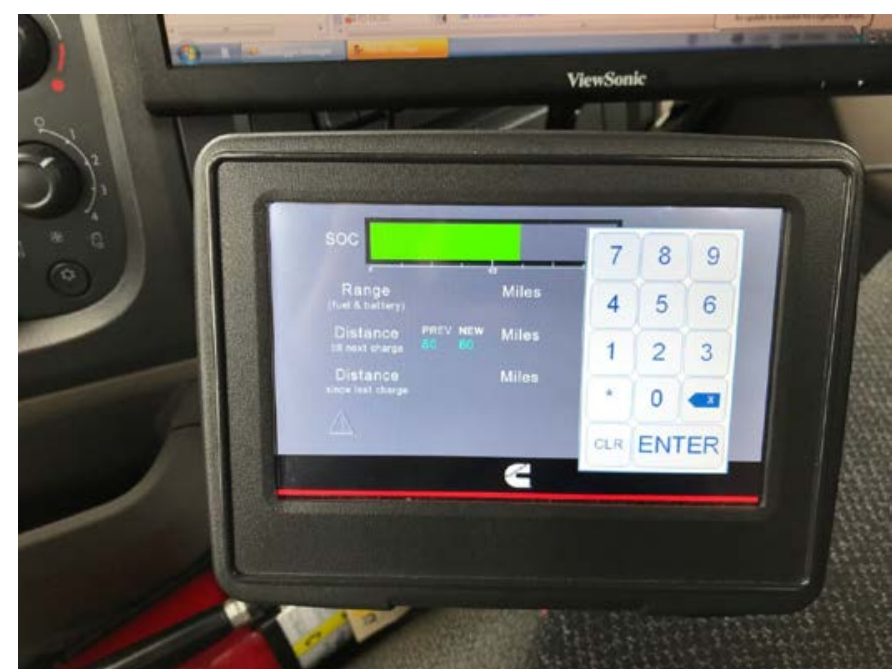

Figure 4 Human-Machine-Interface for driver to enter the mission distance

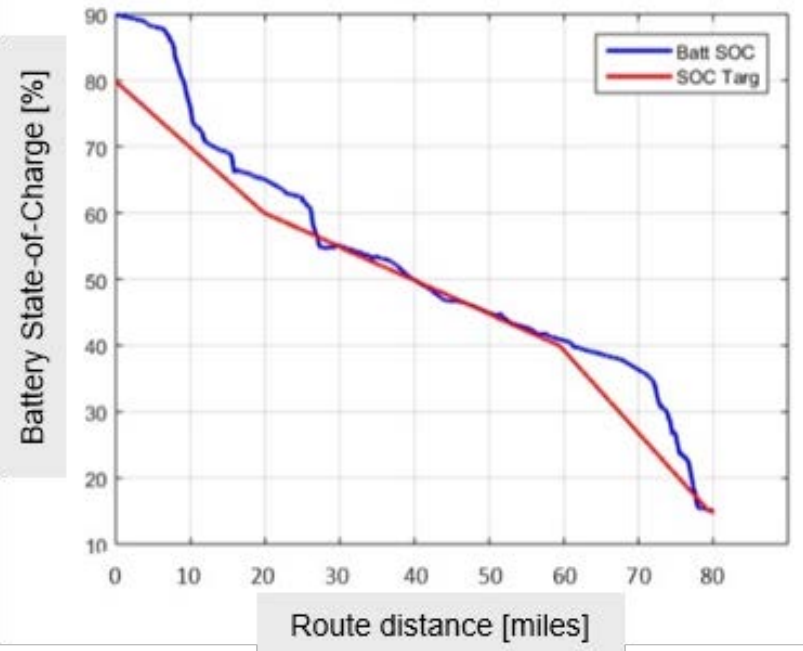

Figure 5 Typical SOC target trajectory for a mission

Another challenge is to reduce the emissions of the range extender. The conversion efficiency of the range extender aftertreatment is best at high temperatures, whereas below the light-off temperature, the conversion efficiency is extremely low. For Class 6 P\&D vehicles, the mission duration varies from 5-10 hours per day. If the control strategy is such that the range extender turns on early in the day and turns on again a few hours later, much higher emissions (especially nitrogen oxides $\left[\mathrm{NO}_{\mathrm{x}}\right]$ ) will be observed, as shown in Figure 6. The results indicate that reducing the number of range extender stops and starts is preferable to minimize emissions. Figure 7 shows emissions from a single range extender start during the mission. It can be observed that system output $\mathrm{NO}_{\mathrm{x}}$ is much lower compared to the multiple start/stop case. Furthermore, since the range extender will only be turned on once during the mission, the SOC tracking will run the range extender in the high-power region, which is more thermally efficient and where the exhaust temperature is higher, resulting in higher aftertreatment conversion efficiency [4].
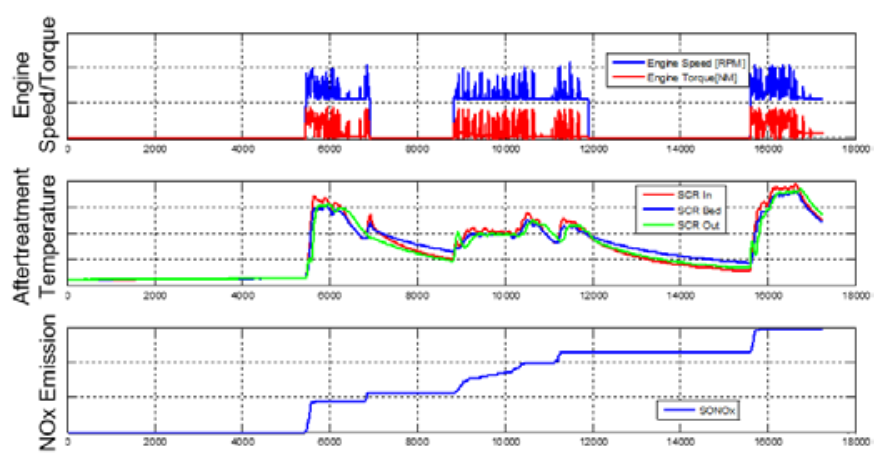

Figure $6 \mathrm{NO}_{\mathrm{x}}$ emissions for multiple range extender start/stop with long duration
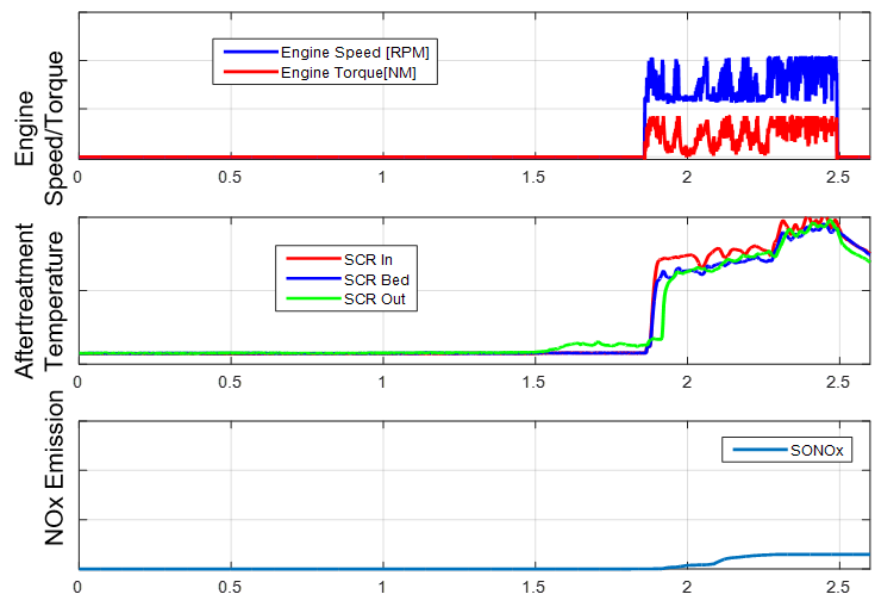

Figure $7 \mathrm{NO}_{\mathrm{x}}$ emissions for single range extender start throughout a mission

\section{Drive Cycle Simplification for Track Testing}

The NREL 80-mile workday cycle developed to evaluate the hybrid truck is representative of daily commercial P\&D operation, including dwell time. It covers 80 miles in approximately 8.5 hours but contains less than 3 hours of total driving time. This cycle is very useful for vehicle simulation to evaluate hybrid component behavior, emissions controls, and accessory loads; however, it is not practical to include so much idling time in a test cycle for vehicle dynamometer or track testing due to time and cost considerations. It was therefore necessary to modify the existing workday cycle and create a drive cycle appropriate for track testing to quantify fuel savings from hybridization.

NREL first removed zero-speed time to reduce the total cycle duration without impacting performance characteristics. In addition to compressing the cycle to reduce dwell time, simplification was needed to ensure the driver could follow the speed profile closely while reserving some attention for steering the vehicle and avoiding hazards. Existing approaches to simplifying the cycle, such as a moving average or downsampling, had significant impact on the overall characteristics of the drive cycle, diminishing its representative nature.

NREL developed an "adaptive decimation" method to strategically reduce the complexity of a speed profile while minimizing the overall impact to key cycle metrics - kinetic intensity, driving average speed, stops per mile, etc. This method identifies critical inflection points in 
the speed profile, such as the start of an acceleration or deceleration event, and interpolates between them to simplify the profile. The most important dynamic driving behavior during major acceleration and deceleration events is retained while minor fluctuations in speed (during cruise events, for instance) are ignored, striking a balance between drivability and adherence to the representative cycle. The degree of simplification is controlled by the amount of speed change $(\Delta \mathrm{mph})$ that defines adjacent critical speed points.

Cummins evaluated several iterations of the adaptive decimated cycle using the Cummins powertrain model to ensure that the relative impact on fuel efficiency (REEV fuel efficiency relative to a conventional vehicle) was minimized. Cummins selected cycle decimation with a $\Delta 7.5$-mph threshold as the best option for track testing. A section of the resulting adaptive decimated cycle is shown in Figure 8, overlaid on the compressed 80-mile workday cycle.

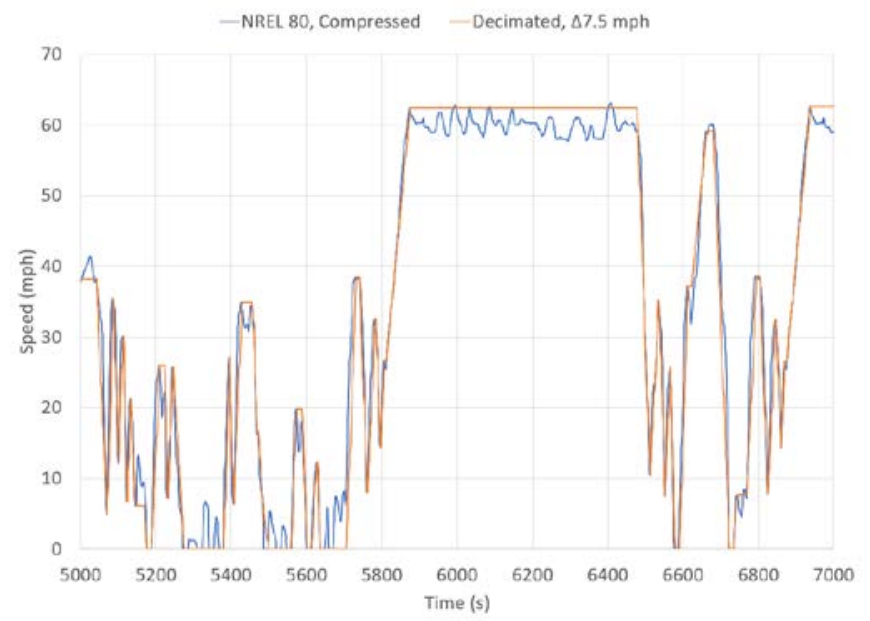

Figure 8 Sample of the NREL 80-mile workday cycle (compressed) and adaptive decimated cycle $(\Delta 7.5 \mathrm{mph})$

Table 1 shows the results of vehicle simulation using the original and modified drive cycles. The difference in fuel consumption reduction and total energy of the original NREL 80 cycle compared to the other two cycles comes from the additional energy used by accessories during long idling portions of the full-length original cycle, which were removed from the simplified cycles.

Table 1 Simulated fuel consumption reduction and total consumed electric energy of the original cycle, compressed cycle, and decimated cycle

\begin{tabular}{|l|c|c|}
\hline & $\begin{array}{c}\text { Simulated Fuel } \\
\text { Consumption } \\
\text { Reduction }\end{array}$ & $\begin{array}{c}\text { Simulated Total } \\
\text { Electric Energy } \\
(\mathbf{k W h})\end{array}$ \\
\hline NREL 80, original & $68.0 \%$ & 136 \\
\hline NREL 80, compressed & $64.2 \%$ & 124 \\
\hline NREL 80, decimated $\triangle 7.5 \mathrm{mph}$ & $65.8 \%$ & 121 \\
\hline
\end{tabular}

Whereas the original NREL 80 cycle requires the driver to change speed 9,090 times, the adaptive decimated cycle $\Delta 7.5 \mathrm{mph}$ requires only 288 speed changes. By this metric, the adaptive decimated cycle is $97 \%$ simpler. The cost of this simplicity is reduced kinetic intensity. In this case, kinetic intensity was reduced by $25.8 \%$, from $0.359 \mathrm{mi}^{-1}$ to $0.266 \mathrm{mi}^{-1}$. Lower kinetic intensity of the simplified drive cycle was a concern because kinetic intensity correlates to energy consumption, and therefore hybrid benefit [5]. The $\Delta 7.5-\mathrm{mph}$ decimation level was chosen, in part, on the expectation that test track drivers would inadvertently reintroduce some kinetic intensity through overcorrection in attempting to closely follow the cycle speed trace. A comparison of cycle metrics in Table 2-for the original cycle, decimated cycle as defined, and decimated cycle as driven by human drivers - validates this hypothesis.

Table 2 Comparison of kinetic intensity and driving average speed for the original cycle and decimated cycle (as defined and as driven)

\begin{tabular}{|l|c|c|}
\hline & $\begin{array}{c}\text { Kinetic } \\
\text { Intensity } \\
\text { (mi }^{-1} \text { ) }\end{array}$ & $\begin{array}{c}\text { Driving } \\
\text { Average Speed } \\
\text { (mph) }\end{array}$ \\
\hline NREL 80, original & 0.359 & 31.9 \\
\hline $\begin{array}{l}\text { NREL 80, decimated } \Delta 7.5 \mathrm{mph} \\
\text { (as defined) }\end{array}$ & 0.266 & 32.7 \\
\hline $\begin{array}{l}\text { NREL 80, decimated } \Delta 7.5 \mathrm{mph} \\
\text { (as driven, conventional vehicle) }\end{array}$ & 0.395 & 32.6 \\
\hline $\begin{array}{l}\text { NREL 80, decimated } \Delta 7.5 \mathrm{mph} \\
\text { (as driven, REEV) }\end{array}$ & 0.367 & 33.1 \\
\hline
\end{tabular}

\section{Mobile DEVCon Automated Driving System}

The mobile Direct Electronic Vehicle Control (DEVCon) automated driving system is used for highly repeatable on-track fuel consumption testing, such as SAE J1321 and SAE J1526 [6,7]. Originally developed for chassis dynamometer applications, the mobile DEVCon system further incorporates braking control installed in the vehicle. DEVCon applies an electronic accelerator pedal position signal directly to the vehicle's engine control unit and eliminates the variation normally introduced by a human driver [8]. Deceleration control is performed by reproducing the driver's brake pedal position. The system maintains a human driving element by recording the driver's inputs on a pre-run cycle. This is programmed into the vehicle during the test and allows the robot to make small corrections for changes in ambient conditions. This results in increased repeatability in the most demanding transient cycles.

Driving a route in the real world provides simplicity, as the external environment coerces the driver behavior; the driver can choose his/her desired speed and stop for breaks. While the drive cycle for this program was reduced and simplified from 8.5 hours to less than 3 hours, replicating a recorded cycle on a closed track requires a driver's intense concentration for the entire duration of the cycle, without break. The DEVCon system ensures this is done only once per vehicle and relieves the driver of the cognitive task of maintaining required speed for lengthy and complicated test cycles. Figure 9 shows the variability of vehicle speed and accelerator pedal position for human drivers compared to the variability of vehicle speed and accelerator pedal position of the DEVCon autonomous system in a previous fuel economy test. 

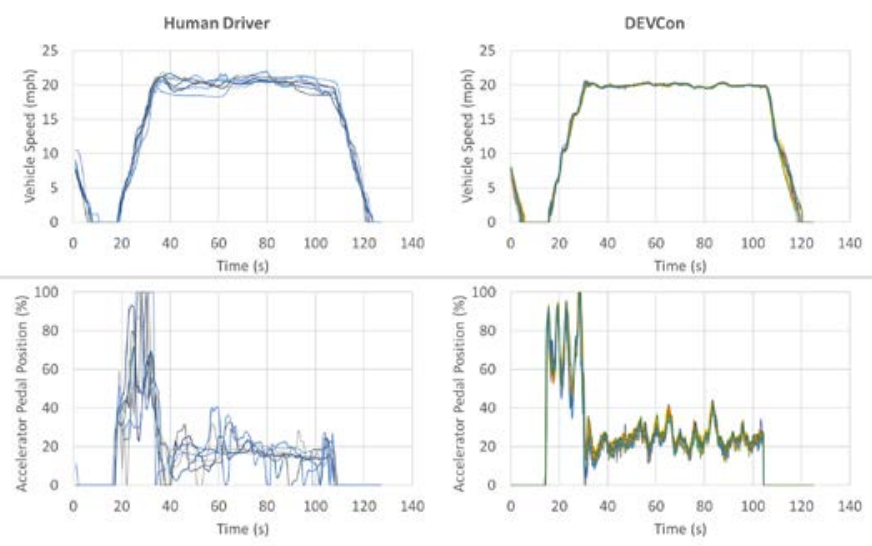

Figure 9 Comparison of vehicle speed (top) and accelerator pedal position (bottom) from repeated test runs for human drivers (left) and automated DEVCon system (right)

In demonstrating a mild hybrid compared to a conventional diesel vehicle, each vehicle requires different driver input to match the target cycle. Control strategies for regenerative braking and the use of different transmissions require unique accelerator and brake pedal inputs for each vehicle. The J1526 procedure calls for the drivers to switch vehicles during testing. This is no longer applicable because the input to each vehicle originates from the same human driver. During testing, the driver only steers the vehicle over an 8.5-mile track with 3-mile radius turns. Simply put, the driver's steering input differences are negligible for this testing. Additionally, the tuning of the DEVCon controls is identical in each vehicle. Therefore, each vehicle responds to day-to-day variations in the same way. The mobile DEVCon system ensured the best possible repeatability for comparing the fuel consumption differences in this project.

\section{Vehicle Track Testing}

SwRI conducted track testing for the project following SAE J1526 protocol for vehicle-to-vehicle fuel economy comparison. The track testing was conducted outdoors on an 8.5-mile asphalt track at Continental Tire North America's Uvalde Proving Grounds. A conventional Class 6 diesel truck was used as the baseline to measure fuel savings. The baseline truck was of similar size and body style as the hybrid truck. Each truck was ballasted to $4850 \mathrm{lbs} \pm 30 \mathrm{lbs}$ of payload. However, due to the differences in the powertrain, the two trucks did not share the same curb weight.

The DEVCon system was installed in each vehicle and used to record the accelerator and brake pedal positions as the human driver followed the target speed profile on the test track. The automated control system was employed to replicate the recorded speed profile for three subsequent test runs for each vehicle. Approximately one week of calibration tests were conducted to record the cycle trace in each truck and tune both trucks for maximum repeatability. After several practice runs to verify consistent performance, testing began.

Fuel consumption was measured by massing an externally mounted secondary fuel tank. A relay connected to the data acquisition system switched between the primary and external tanks at the start of each cycle. The test cycle always began with the hybrid truck's battery pack at $97 \%$ SOC. Air pressure in each tire was checked before every test and maintained at $100 \mathrm{psi}$ for both the drive and steer axle.

Another important control specified in the $\mathrm{J} 1526$ procedure is weather conditions. A portable weather station was set up adjacent to the track that measured wind speed, temperature, humidity, and wind direction. The J1526 procedure calls for a maximum average wind speed of $12 \mathrm{mph}$ and a maximum single gust of $15 \mathrm{mph}$. Also, ambient temperature could not exceed $100^{\circ} \mathrm{F}$ or fall below $40^{\circ} \mathrm{F}$. All testing was performed at an average wind speed between $4.57 \mathrm{mph}$ and $7.18 \mathrm{mph}$, with maximum single gusts between $8.86 \mathrm{mph}$ and $13.86 \mathrm{mph}$. Ambient temperature during testing was at a minimum of $73^{\circ} \mathrm{F}$ and a maximum of $85^{\circ} \mathrm{F}$. The test cycle started at approximately the same time every day for similar weather conditions, within about half an hour. Testing never occurred in the rain.

In the J1526 test procedure, there are ordinarily two segments made up of a variable number of runs. The more runs in a segment, the more statistically accurate the results are. Between the first and second segment, the drivers switch trucks as a means to reduce the statistical effect of human bias. Because the DEVCon automated driving system maintains the same driver input between the two trucks, only one segment was completed. Testing was completed after finishing three successful runs.

\section{Results}

After reviewing the vehicle data from the three runs with the DEVCon system, the testing was deemed valid according to the J1526 standard. Table 3 shows the cycle-to-cycle variation of the three runs in terms of fuel consumption reduction. Table 4 summarizes the testing and simulation results. Due to the difference between the driver model used in simulation and the DEVCon system used in testing, the kinetic intensity of the resulting duty cycles is slightly different. However, the average speed for the cycle is kept the same. The fuel consumption reduction percentage shows an excellent match (less than $1 \%$ difference) between the simulated results and testing results. Simulation estimated $65.8 \%$ reduction in fuel for REEV vs. conventional vehicle and the measured reduction from vehicle tests was $65.6 \%$. If one examines the total electric energy consumption and the absolute fuel consumption between the simulation and the vehicle test results-simulated conventional versus tested conventional, for example - there is close to $8 \%$ difference. The increases in absolute fuel consumption between simulation and testing are proportionally equal for the conventional vehicle and REEV, offsetting each other in the fuel consumption reduction calculation. The causes of the fuel consumption discrepancy between simulation and track testing are: (1) In simulation, the vehicle is assumed to run on a flat surface. However, the assumption is not true for the test track. (2) The accessory load is not accurately modeled for either vehicle in the simulation.

Table 3 Cycle-to-cycle variation of the test runs

\begin{tabular}{|c|c|}
\hline Test Run & Fuel Consumption Reduction \\
\hline Run 1 & $65.33 \%$ \\
\hline Run 2 & $65.81 \%$ \\
\hline Run 3 & $64.55 \%$ \\
\hline
\end{tabular}


Dynamometer," SAE Technical Paper 2016-01-0907, 2016, doi: 10.4271/2016-01-0907.

\section{Contact Information}

John Kresse is a technical leader for commercial electrified vehicles in the Research and Technology Department at Cummins in Columbus, Indiana. John is the past Principal Investigator for the ETREE program. His current focus is leading an international team of engineers developing practical solutions for applying electric vehicle technology to medium- and heavy-duty commercial vehicles. He may be reached at john.kresse@cummins.com.

$\mathbf{K e ~} \mathbf{L i}$ is a system and controls technical specialist engineer in the Research and Technology Department of Cummins in Columbus, Indiana. Ke's research interests are in the area of system integration and controls of the electrification for medium- and heavy-duty commercial vehicles. He may be reached at k.li@,cummins.com.

\section{Summary}

While the wide market adoption of BEVs as commercial vehicles is heavily dependent on continuous progress of battery technology and ubiquitous fast-charging infrastructure, REEVs are already energy efficient, operationally viable substitutes for conventional vehicles. In this paper, the applicability of REEV technology to the Class 6 P\&D market was demonstrated. A range-extended EV was designed and built, along with a novel range extender control strategy that optimizes the grid energy utilization and minimizes the system tailpipe emissions. NREL developed a method of simplifying the representative daily drive cycle that is practical for track or dynamometer testing while maintaining the real-world attributes needed to evaluate performance. The REEV was benchmarked with its conventional counterpart following the SAE J1526 fuel economy test standard and the results show the REEV was able to achieve a $65 \%$ fuel consumption reduction compared to a conventional vehicle in the same class.

\section{References}

1. Duran, A., Li, K., Kresse, J., and Kelly, K., "Development of 80- and 100- Mile Work Day Cycles Representative of Commercial Pickup and Delivery Operation," SAE Technical Paper 2018-01-1192, 2018, doi:10.4271/2018-01-1192.

2. National Renewable Energy Laboratory, "Fleet DNA Project Data," www.nrel.gov/fleetdna, 2019.

3. National Renewable Energy Laboratory, "DRIVE Analysis Tool Generates Custom Vehicle Drive Cycles Based on Real-World Data," https://www.nrel.gov/docs/fy13osti/54507.pdf, April 2013.

4. Thornton, M., Duran, A., Ragatz, A., Cosgrove, J. et al., "Data Collection, Testing, and Analysis of Hybrid Electric Trucks and Buses Operating in California Fleets," https://www.nrel.gov/docs/fy15osti/62009.pdf, June 2015.

5. O'Keefe, M.P., Simpson, A., Kelly, K.J., and Pederson, D.S., "Duty Cycle Characterization and Evaluation Towards Heavy Hybrid Vehicle Applications," SAE Technical Paper 2007-010302, 2007, doi:10.4271/2007-01-0302.

6. SAE International Surface Vehicle Recommended Practice, "Fuel Consumption Test Procedure - Type II," SAE Standard J1321, Rev. Feb. 2012.

7. SAE International Surface Vehicle Recommended Practice, "SAE Fuel Consumption Test Procedure (Engineering Method)," SAE Standard J1526, Rev. Sep. 2015.

8. Blanks, M., "Technical Approach to Increasing Fuel Economy Test Precision with Light Duty Vehicles on a Chassis
Kenneth Kelly has over 25 years of transportation research experience at NREL, where he currently manages NREL's Commercial Vehicle Technologies team partnering with government and industry to develop advanced vehicle technologies for mediumand heavy-duty applications. While at NREL, Ken has managed and conducted research in a wide array of advanced vehicle and transportation technologies. He holds M.S. and B.S. degrees in Mechanical Engineering from Ohio University. He may be reached at Kenneth.Kelly@nrel.gov.

Matthew Jeffers is a research engineer in NREL's Center for Integrated Mobility Sciences who focuses on evaluating performance, cost and operational impacts of advanced technology vehicles, including battery electric and fuel cell electric truck and bus fleets. He may be reached at Matthew.Jeffers@nrel.gov.

Michael Kader is a research engineer in the Automotive Propulsion Systems Department at Southwest Research Institute in San Antonio, Texas. Currently, he is focused primarily in testing efficiency of current and future powertrain architectures. Michael was the principal investigator for the development of the mobile DEV con ${ }^{\mathrm{TM}}$ system. He may be reached at Michael.Kader@SwRI.org.

\section{Acknowledgments}

This work was authored, in part, by the National Renewable Energy Laboratory, operated by Alliance for Sustainable Energy, LLC, for the U.S. Department of Energy (DOE) under Contract No. DE-AC3608GO28308. Funding and technical assistance provided by U.S. Department of Energy's Vehicle Technologies Office under contract number DE-FOA-0001349. The views expressed in the article do not necessarily represent the views of the DOE or the U.S. Government. The U.S. Government retains and the publisher, by accepting the article for publication, acknowledges that the U.S. Government retains a nonexclusive, paid-up, irrevocable, worldwide license to publish or reproduce the published form of this work, or allow others to do so, for U.S. Government purposes.

\section{Abbreviations}

$\begin{array}{ll}\text { BEV } & \text { battery-electric vehicle } \\ \text { DEVCon } & \text { Direct Electronic Vehicle Control } \\ \text { DOC } & \text { diesel oxidation catalysts } \\ \text { DOE } & \text { Department of Energy }\end{array}$




$\begin{array}{ll}\text { DPF } & \text { diesel particulate filter } \\ \text { ETREE } & \text { electric truck with range-extending engine } \\ \text { EV } & \text { electric vehicle } \\ \text { kW } & \text { kilowatt } \\ \text { kWh } & \text { kilowatt-hour } \\ \text { L } & \text { liter } \\ \text { Ibs } & \text { pounds } \\ \text { mi } & \text { miles } \\ \text { mph } & \text { miles per hour } \\ \text { Nm } & \text { Newton meter } \\ \text { NMC } & \text { nickel-manganese-cobalt } \\ \text { NOx } & \text { nitrogen oxides } \\ \text { NREL } & \text { National Renewable Energy Laboratory } \\ \text { P\&D } & \text { pickup and delivery } \\ \text { PM } & \text { permanent magnet } \\ \text { psi } & \text { pounds per square inch } \\ \text { REEV } & \text { range-extended electric vehicle } \\ \text { SCR } & \text { selective catalytic reduction } \\ \text { SOC } & \text { state of charge } \\ \text { SwRI } & \text { Southwest Research Institute } \\ & \end{array}$

